\title{
Kadıncık Deresi’ndeki (Çamlıyayla-Mersin) Balık Yoğunluğu ve Biyoması
}

\author{
Ahmet Şeref KORKMAZ ${ }^{1}$ \\ Geliş Tarihi : 22.11.2004
}

\begin{abstract}
Öz: Bu çalışmada, Tarsus Akarsuyu'nun önemli kollarından birisi olan Kadıncık Deresi'nin 16 km'lik koruma altına alınan bölümünde bulunan balık türlerinin yoğunluğu ve biyoması ile birlikte yaş, boy ve ağırlık kompozisyonları ve dağ alabalığının dağılımı araştııımıştır. Kadıncık Deresi'nin incelenen bölümünde, 09-18.09.2002 tarihleri arasında yapılan örneklemelerde dağ alabalığı (Salmo trutta macrostigma Dumeril, 1858) ve gökkuşağı alabalığı (Oncorhynchus mykiss Walbaum, 1792) olmak üzere iki tür avlanmıştır. İlk dağ alabalığına derenin 8,6 . km.'sinde rastlanmıştır. Bu noktadan kaynağa doğru balık miktarının arttığı gözlenmiştir. Kadıncık Deresi'nden avlanan 64 adet dağ alabalığı (Salmo trutta macrostigma Dümeril, 1858) beş, 15 adet gökkuşağı alabalığı (Oncorhynchus mykiss Walbaum, 1792) iki yaş grubundan oluşmuștur. Yoğunluk ve biyomas tahminleri için Kadıncık Deresi'nin incelenen bölümü, dip yapısı ve habitata göre dört tabakaya ayrılmıştır. Bu tabakalarda $200 \mathrm{~m}$ uzunluğunda 36 örnekleme yeri seçilmiş ve elektroşokla tek avlama yapılmıştır. Elde edilen verilere tek avlı ayrılmaya dayalı metot uygulanarak dağ alabalığı ve gökkuşağı alabalığının yoğunluğu sırasıyla 28 adet/ha ve 3,47 adet/ha, biyoması ise sırasıyla 2,55 kg/ha ve 1,56 kg/ha olarak tahmin edilmiştir. Kadıncık Deresi'ndeki toplam balık yoğunluğu ve biyoması sırasıyla $32 \mathrm{adet} / \mathrm{ha}$ ve $4,1 \mathrm{~kg} / \mathrm{ha}$ olarak saptanmıştır.
\end{abstract}

Anahtar Kelimeler: Dağ alabalığı (Salmo trutta macrostigma), gökkuşağı alabalığı (Oncorhynchus mykiss), yoğunluk, biyomas, Kadıncık Deresi, Türkiye

\section{Density and Biomass of Fish in Kadıncık (Çamlıyayla-Mersin) Brook}

\begin{abstract}
In this study, age, length and weight distributions together with density and biomass of fish species in the studied section for $16 \mathrm{~km}$ of the Kadıncık Brook which is one of the important tributaries of the Tarsus Stream were researched. In addition to these, distribution area of brown trout in the brook was also investigated. In the studied section of Kadıncık Brook, were two species caught to be brown trout (Salmo trutta macrostigma Dümeril, 1858) and rainbow trout (Oncorhynchus mykiss Walbaum, 1792) in the period of September 9-18, 2002. First brown trout was caught at $8.6^{\text {th }} \mathrm{km}$ of the Kadıncık Brook. It was observed that fish quantity increased from that point towards headwater. Sixtyfour nos. brown trout and 15 nos. rainbow trout caught from the Kadıncık Brook were determined to be consist of five age-groups and two age-groups, respectively. To estimate density and biomass, the studied section of Kadıncık Brook according to nature of bottom and habitat was separated into four strata. Thirty-six sampling sites at length for $200 \mathrm{~m}$ in these strata were selected and in the selected sections, carried out single catch by electrofishing. Removal method based on single-pass electrofishing was carried out to obtained data. Density and biomass were estimated as 28 inds. $\mathrm{ha}^{-1}$ and $2,55 \mathrm{~kg} \mathrm{ha}^{-1}$ for brown trout and 3,47 inds. ha ${ }^{-1}$ and $1,56 \mathrm{~kg} \mathrm{ha}^{-1}$ for rainbow trout, respectively. Density and biomass of fish in Kadıncık Brook were estimated as 32 inds. ha ${ }^{-1}$ and $4,1 \mathrm{~kg} \mathrm{ha}^{-1}$, respectively.
\end{abstract}

Key Words : Brown trout (Salmo trutta macrostigma), rainbow trout (Oncorhynchus mykiss), density, biomass, Kadıncık Brook, Turkey

\section{Giriş}

Akarsulardaki balık populasyonlarının yoğunluk ve biyomas gibi kantitatif özelliklerinin bilinmesi, söz konusu su kaynağındaki biyolojik çeşitliliğin korunması ve su kaynağından ekonomik olarak yararlanma açısından önem taşımaktadır.

Su kaynaklarındaki balık populasyonlarının yapısı, çevre koşulları ve aynı ortamı paylaştıkları farklı balık türlerinin beslenme, büyüme, üreme, göç ve ölüm gibi biyolojik özellikleri ile de ilişkilidir. Bu nedenle, ekonomik öneme sahip olan balık türlerine ait populasyonlar ile ilişk içinde bulundukları diğer populasyonlar ve bulundukları ortamla ilgili kapsamlı ve sürekli araştırmalar yapılması gereklidir. Böylece, populasyonların mevcut durumlarının ortaya konularak, balıkçılık yönetimi açısından alınması gerekli tedbirlerin belirlenmesi mümkün olacaktır. Ancak,
Türkiye'deki akarsularda bulunan balık stoklarının tespiti ve bu stoklardan optimum düzeyde yararlanmaya Işık tutacak çalışmalar (Ölmez 1992, Korkmaz ve Atay 1997, Korkmaz ve ark. 1998) oldukça azdır.

Dağ alabalığı (Salmo trutta macrostigma Dümeril, 1858), Türkiye'deki akarsularda bulunan ekonomik öneme sahip doğal balık türlerinden en önemlisidir. Dağ alabalığı, Türkiye'de büyük bir popülariteye sahiptir. Yerel balıkçılık açısından etinin lezzetli olması ve çeşitli hastalıklar için tedavi edici olarak kullanılmasının yanı sıra sportif balıkçıık açısından da büyük öneme sahip bir türdür. Bu nedenle, gökkuşağı alabalığının iki katı fiyatla alıcı bulabilmektedir. Dağ alabalığının bu özellikleri; bulunduğu birçok akarsuda dinamit, el bombası, karpit, elektrik ve ışıkla avcılık gibi yasal olmayan yöntemlerle avcılığını cazip hale getirmiştir.

${ }^{1}$ Ankara Üniv., Ziraat Fak., Su Ürünleri Bölümü-Ankara 
Özellikle, üreme döneminde ergin bireyler üzerinde yoğunlaşan aşırı avcılık, populasyona yeni birey katılımının düşük olmasına ve populasyonlarının küçülmesine neden olmaktadır. Ayrıca, sulama, içme ve kullanma suyu temini amacıyla doğal habitatı olan akarsuların barajlarla kesilmes de üreme habitatlarının bozulmasına yol açmaktadır. Bu nedenle, akarsulardaki doğal dağ alabalığı populasyonlarının yoğunluk ve biyomas gibi kantitatif özelliklerinin sürekli izlenerek, mevcut durumlarının ortaya konması, balıkçılık yönetimi açısından gerekli tedbirlerin zamanında alınmasını ve uygulanmasını sağlayacaktır.

Tarsus Akarsuyu'nu oluşturan iki önemli kaynaktan birisi olan ve aynı zamanda alabalığı ile de meşhur olan Kadıncık Deresi, gerek sportif balıkçılık gerekse diğer yaban hayatıyla birlikte turizm potansiyeline sahiptir (Saraçoğlu 1990). Ancak, Türkiye'de doğal olarak bulunduğu diğer akarsulardaki gibi Kadıncık Deresi'ndeki dağ alabalığı populasyonu da aşırı avcılıktan dolayı küçülme tehdidi ile karşı karşıyadır. Bu nedenle, derenin kaynak kısmı ile Böğürtlendere arasında kalan 16 km'lik bölümü Milli Parklar Av-Yaban Hayatı Genel Müdürlüğü tarafından koruma altına alınmış ve her türlü avcılığa kapatılmıştır.

Kadıncık Deresi'ndeki balık türlerine ilişkin olarak daha önce yapılmış herhangi bir çalışma bulunmadığından, yürütülen bu araştırma, hem populasyonların mevcut durumlarının ortaya konması ve hem de sürdürülebilir yararlanma için yapılması gereken çalışmalara, balıkçılık yönetimi açısından uygulanması gereken tedbirlere ışık tutması, hem de yoğunluk ve biyomas tahminlerinde tek avlamaya dayalı ayrıma metodunun uygulamaya konulması açısından önem taşımaktadır.

\section{Materyal ve Yöntem}

Araştırma, 9-18.Eylül.2002 döneminde Çamlıyayla (Mersin) ilçesinin sınırları içerisindeki Kadıncık Deresi'nin kaynak bölümü ile Böğürtlendere arasında kalan ve Milli Parklar Av-Yaban Hayatı Genel Müdürlüğünce koruma altına alınan 16 km'lik bölümde yürütülmüştür. Derenin incelenen bölümü; kenar yapısı, akış hızı, derinliği, genişliği ve dip yapısı gibi fiziksel özellikler ile habitatın yapısına göre dört tabakaya ayrılmıştır (Hankin 1984). A tabakasında 25, B tabakasında 1 , C tabakasında 14 ve D tabakasında 40 bölüm olmak üzere $200 \mathrm{~m}$ uzunluğunda 80 bölüm oluşturulmuştur (Gelwick 1990). Bu bölümlerden sırasıyla 13 1,5 ve 18 bölüm olmak üzere toplam 37 bölüm (akarsuyun $\%$ 46'sı), tabakalar içerisinde basit tesadüfi örnekleme yöntemine göre seçilmiştir (Şekil 1).

Örnek alma yerlerinde; suyun sıcaklığı, derinliği ve hızı ile akarsu genişlikleri örnekleme yerinde, yerinde yapılamayan suyla ilgili bazı kimyasal özellikler için örnek alınarak, analizler laboratuarda yapılmıştır (Çizelge 1).

Seçilen bölümlerde, balıklar, $20 \mathrm{~kg}$ ağılığında, anodu $0,5 \mathrm{~m}$ çapında ve transformatörlü portatif jeneratör (650 watt, $2 \mathrm{~A}, 50 \mathrm{~Hz}$ ve 3000 dev./dk) kullanılarak yakalanmıştır (Zalewski 1985, Korkmaz ve Atay 1997). Avlamalar, alt ve üst sınırları düğümden düğüme $10 \mathrm{~mm}$ göz açıklığında sabit ağlarla kapatılmış olan 200 m'lik akarsu bölümlerinde, teorik ve pratik eğitim almış personel tarafından akıntıya karşı gidilerek yapılmıştır. Avlama işleminin akıntıya karşı yapılması, temiz suda avlanma olanağı sağlamıştır (Halyk ve Balon 1983, Peterson ve Cederholm 1984, Coles ve ark. 1985). Araştırma süresince anot ve katodun aynı şahıslar tarafından kullanılmasına özel itina gösterilmiştir. Avlamada, anodu kullanan bir kişi ile balık kepçesini kullanan iki kişi yan yana yürümüşler, diğer bir kişi de katodu kullanmış ve iki kutup arasında meydana gelen elektiriki alanda bayılan balıklar kepçelerle toplanmıştır (Penczak ve ark. 1981). Dere yatağının kayalık ve taşlık olması nedeniyle, seçilen akarsu bölümlerinde tek avlama yapılmıştır (Seber 1973). Balıkların avlandığı yüzey alanını hesaplayabilmek için her akarsu bölümünde 10-20 m'de bir genişlik ölçülmüştür (Neves ve Pardue 1983). Su hızı, yüzdürme ve saati durdurma esasına göre tahmin edilmiştir (Gorman ve Karr 1978).

Tarım ve Köyişleri Bakanlığı'ndan alınan izne göre, avlanan balıkların canlı olarak suya iadesi söz konusu olduğundan, balıkların boyu ( $\mathrm{mm}$ duyarlıkta) ve ağırlığı $(0,01$ g duyarlıkta) avlandıkları yerlerde ölçülmüş ve yaş tayini için pul örnekleri alınmıştır (Lagler 1956).
Şekil 1. Kadıncık Deresi'nin incelenen bölümü ve örnek avlaması yapılan akarsu bölümleri 
Çizelge 1. Kadıncık Deresi'ndeki örnekleme yerlerinin suyla ilgili bazı fiziksel ve kimyasal özellikleri

\begin{tabular}{|c|c|c|c|c|c|c|}
\hline İstasyonlar & Su sıcaklığı $\left({ }^{\circ} \mathrm{C}\right)$ & $\mathrm{pH}$ & $\mathrm{EC}(\mu \mathrm{hos} / \mathrm{cm})$ & Çözünmüş $\mathrm{O}_{2}(\mathrm{mg} / \mathrm{L})$ & Bulanıklık (JTB) & Su hızı (m/s) \\
\hline \multicolumn{7}{|c|}{ Tabaka $\mathrm{A}(\mathrm{N}=25, \mathrm{n}=13)$} \\
\hline 1 & 11 & 7,8 & 121 & 9,4 & 4 & 1,2 \\
\hline 2 & 11 & 7,8 & 142 & 9,5 & 4 & 1,1 \\
\hline 5 & 11 & 7,7 & 114 & 9,6 & 3 & 1,2 \\
\hline 6 & 11 & 7,6 & 120 & 9,5 & 3 & 1,4 \\
\hline 8 & 11 & 7,8 & 104 & 9,4 & 4 & 1,5 \\
\hline 10 & 13 & 7,6 & 108 & 9,7 & 3 & 1,4 \\
\hline 12 & 13 & 7,8 & 115 & 9,8 & 3 & 1,3 \\
\hline 15 & 13 & 7,6 & 139 & 9,6 & 2 & 1,4 \\
\hline 16 & 13 & 7,7 & 117 & 9,5 & 3 & 1,4 \\
\hline 18 & 13 & 7,8 & 113 & 9,4 & 3 & 1,3 \\
\hline 20 & 13 & 7,8 & 114 & 9,7 & 4 & 1,4 \\
\hline 23 & 12 & 7,6 & 109 & 9,8 & 3 & 1,5 \\
\hline 25 & 13 & 7,8 & 103 & 9,3 & 3 & 1,2 \\
\hline \multicolumn{7}{|c|}{ Tabaka B (N=1, n=1) } \\
\hline 26 & 13 & 7,5 & 130 & 9,1 & 6 & 0,6 \\
\hline \multicolumn{7}{|c|}{ Tabaka $\mathrm{C}(\mathrm{N}=14, \mathrm{n}=5)$} \\
\hline 29 & 11 & 7,6 & 94 & 9,6 & 5 & 1,5 \\
\hline 31 & 13 & 7,8 & 111 & 9,5 & 4 & 1,3 \\
\hline 33 & 13 & 7,8 & 125 & 9,4 & 4 & 1,2 \\
\hline 38 & 13 & 7,7 & 122 & 9,7 & 3 & 1,0 \\
\hline 40 & 13 & 7,6 & 110 & 9,8 & 3 & 1,1 \\
\hline \multicolumn{7}{|c|}{ Tabaka $\mathrm{D}(\mathrm{N}=25, \mathrm{n}=18)$} \\
\hline 43 & 13 & 7,8 & 117 & 9,6 & 2 & 1,2 \\
\hline 44 & 12 & 7,6 & 129 & 9,9 & 3 & 1,2 \\
\hline 45 & 12 & 7,7 & 131 & 10,0 & 3 & 1,3 \\
\hline 48 & 11 & 7,5 & 127 & 9,8 & 2 & 1,3 \\
\hline 49 & 12 & 7,6 & 142 & 9,7 & 2 & 1,2 \\
\hline 50 & 12 & 7,8 & 119 & 9,5 & 2 & 1,4 \\
\hline 51 & 12 & 7,6 & 111 & 9,6 & 3 & 1,2 \\
\hline 52 & 11 & 7,7 & 133 & 9,5 & 4 & 1,3 \\
\hline 53 & 11 & 7,5 & 109 & 9,6 & 3 & 1,5 \\
\hline 54 & 12 & 7,7 & 126 & 9,5 & 3 & 1,4 \\
\hline 55 & 11 & 7,6 & 118 & 9,7 & 3 & 1,6 \\
\hline 57 & 11 & 7,6 & 109 & 9,8 & 3 & 1,4 \\
\hline 58 & 12 & 7,5 & 134 & 10,2 & 2 & 1,5 \\
\hline 60 & 11 & 7,5 & 129 & 10,4 & 2 & 1,6 \\
\hline 61 & 11 & 7,7 & 117 & 9,9 & 2 & 1,7 \\
\hline 62 & 11 & 7,3 & 138 & 10,0 & 3 & 1,6 \\
\hline 63 & 11 & 7,9 & 127 & 9,8 & 2 & 1,5 \\
\hline 65 & 11 & 7,8 & 140 & 10,1 & 2 & 1,4 \\
\hline
\end{tabular}

Yaş tayini, pulların üzerindeki yaş halkalarının sayılması suretiyle yapılmıştır (Bagenal ve Tesch 1978).

Dere yatağının kayalık-taşlık, hızlı akıntılı ve çalışma sahasının $16 \mathrm{~km}$ olması nedeniyle çok güç olan dere şartları, aynı akarsu bölümünde bir defadan fazla avlanmaya olanak vermediğinden, her akarsu bölümünde tek avlamaya (ayrılmaya) dayalı metot uygulanarak populasyon büyüklüğü (yoğunluğu);

$$
\hat{\mathrm{N}}_{\mathrm{i}}=\frac{\mathrm{C}_{\mathrm{i}}}{\hat{\mathrm{p}}} \quad(\mathrm{i}=1,2,3, \ldots \ldots \ldots . . \mathrm{n})
$$

eşitliğiyle tahmin edilmiştir. Burada;

$$
\begin{aligned}
& \hat{N} \text { : Populasyon büyüklüğünü, } \\
& \text { C : Avlanan balık sayısını ve }
\end{aligned}
$$

$\hat{p}$ : Avlama etkinliğini (1- $\hat{q})$ göstermektedir (Seber 1973). Yukarıdaki eşitlikte, avlama etkinliğinin değeri, Korkmaz ve ark. (1998)'nın benzer dip yapısı ve habitata sahip Hatila
Deresi'nde dağ alabalığı için saptadıkları değer $(\hat{p}=0,63)$ kullanılmıştır. Populasyon büyüklüğü tahminine ait varyans ve $\% 95$ güven sınırları,

$$
\begin{aligned}
& S_{\hat{N}_{i}}^{2}=\hat{N}^{2} \cdot \hat{q} \cdot(1-\hat{q}) \cdot \hat{N} \cdot \hat{p}^{3}+\hat{N}^{2} \hat{q} / \hat{p}+\hat{N} \hat{q}^{2}(5+\hat{q}) / \hat{N}^{2} \hat{p}^{4} \\
& \hat{N}_{i} \pm 1,96 \cdot S_{\hat{N}_{i}}
\end{aligned}
$$

şeklinde hesaplanmıştır (Seber 1973). Her tabakada, istasyon (bölüm) başına düşen ortalama balık miktarı ve istasyonlar (bölümler) arasındaki varyans,

$$
\hat{N}=\sum_{i=1}^{n} \hat{N}_{i} / n \text { ve } S_{\hat{N}}^{2}=\sum_{i=1}^{n}\left(N_{i}-\hat{N}\right)^{2} /(n-1)
$$

eşitliklerinden bulunmuştur. Her tabakadaki (j) toplam balık miktarının tahmini ve varyansı, 


$$
\hat{N}_{j}=\hat{N}_{\times} \times N \quad S_{\hat{N}_{j}}^{2}=\frac{N}{n}(N-n) S_{\hat{N}}^{2}+\frac{N}{n} \sum_{i=1}^{n} S_{\hat{N}_{i}}^{2}
$$
sınırları,

eşitliklerinden bulunmuştur. Tahminin \%95 güven

$\hat{\mathrm{N}}_{\mathrm{i}} \pm 1,96 \cdot \mathrm{S}_{\hat{\mathrm{N}}_{\mathrm{i}}}$ şeklinde bulunmuştur. Toplam balık miktarının tahmini, tahminin varyansı ve $\% 95$ güven sınırları,

$$
\hat{\mathrm{N}}_{\mathrm{T}}=\sum_{\mathrm{j}=1}^{\mathrm{h}} \mathrm{N}_{\mathrm{j}}, \mathrm{S}_{\hat{\mathrm{N}}_{\mathrm{T}}}^{2}=\sum_{\mathrm{j}=1}^{\mathrm{n}} \mathrm{S}_{\hat{\mathrm{N}}_{\mathrm{j}}}^{2} \text { ve } \hat{\mathrm{N}}_{\mathrm{T}} \pm 1,96 \cdot \mathrm{S}_{\hat{\mathrm{N}}_{T}}
$$

şeklinde hesaplanmıştır (Bohlin ve ark. 1989).

Populasyon yoğunluğu $(\hat{N})$, populasyon büyüklüğü tahmininin akarsu yüzey alanına bölünmesiyle bulunmuştur (Seber 1973).

Biyomas;

$\hat{B}=B \times \frac{\hat{N}}{N}$ eşitliğiyle tahmin edilmiştir. Burada;

$\hat{B}$ : Biyomasın tahminini $(\mathrm{kg} / \mathrm{ha})$,

B : Avlanan balıkların ağırlığını ve

$\mathrm{N}$ : Avlanan toplam balık sayısını göstermektedir (Mahon ve ark. 1980).

Yoğunluk ve biyomas tahminlerinde; populasyonun kapalı olduğu, doğum (ya da iç göç) ve ölüm (ya da dış göç) olmadığı ve bütün bireylerin aynı avlanabilirliğe sahip olduğu kabul edilmiştir (Seber 1973).

\section{Bulgular}

Yaş, boy ve ağırlık kompozisyonu: Kadıncık Deresi'nden avlanan dağ alabalığı (Salmo trutta macrostigma) ve gökkuşağı alabalığı (Oncorhynchus mykiss) türlerinin yaş, boy ve ağırlık kompozisyonları Çizelge 2'de verilmiştir.

Çizelge 2 incelendiğinde görüleceği gibi, örneklerde dağ alabalığı 5 , gökkuşağı alabalığı ise 2 yaş grubu ile temsil edilmiştir. Her iki türde de en yüksek oranda temsil edilen yaş grubu, 3' dür. 3 yaşlılar, dağ alabalığında \% 45,31, gökkuşağı alabalığında ise \% 77,78 oranla en yüksek oranda temsil edilmektedir.

Kadıncık Deresi'nden avlanan dağ alabalıkları ve gökkuşağı alabalıklarında çatal boy değeri sırasıyla 12,00$30,50 \mathrm{~cm}$ ve $28,00-40,00 \mathrm{~cm}$, toplam ağırlık değeri ise sırasıyla 19,45-375 g ve283,49-763,48 g arasında dağılım göstermiştir. Her iki türde artan yaşla birlikte boy ve ağırlık değerleri de artmıştır.

Populasyon yoğunluğu ve biyoması: Kadıncık Deresi'ndeki dağ alabalığı (Salmo trutta macrostigma) ve gökkuşağı alabalığının (Oncorhynchus mykiss) yoğunluk ve biyomas tahminlerine ilişkin değerler, Çizelge 3'de verilmiştir.

Çizelge 3 incelendiğinde görüleceği gibi, Kadıncık Deresi'ndeki yoğunluk ve biyomas değerleri; örnekleme istasyonlarına göre gökkuşağı alabalığında sırasıyla 0-53 adet/ha ve 0,0-26,8 kg/ha, dağ alabalığında ise sırasıyla 1879 adet/ha ve 1,8-9,4 kg/ha arasında değişmiştir.

Kadıncık Deresi'ndeki ortalama yoğunluk ve biyomas değerleri dağ alabalığı için sırasıyla 28,25 adet/ha ve 2,55 $\mathrm{kg} / \mathrm{ha}$, gökkuşağı alabalığı için ise sırasıyla 3,47 adet/ha ve $1,56 \mathrm{~kg} / \mathrm{ha}$ olarak tahmin edilmiştir. Kadıncık Deresi'ndeki toplam balık yoğunluğu 32 adet/ha, biyoması ise $4,1 \mathrm{~kg} / \mathrm{ha}$ olarak tahmin edilmiştir.

\begin{tabular}{|c|c|c|c|c|c|c|c|c|}
\hline \multirow[t]{2}{*}{ Yaş grubu } & \multicolumn{4}{|c|}{ Dağ alabalığı } & \multicolumn{4}{|c|}{ Gökkuşağı alabalığı } \\
\hline & $\mathrm{n}$ & $\% \mathrm{n}$ & $\left(\bar{L} \pm S_{\bar{L}}\right)$ & $\left(\overline{\mathrm{W}} \pm \mathrm{S}_{\overline{\mathrm{W}}}\right)$ & $\mathrm{n}$ & $\% n$ & $\left(\overline{\mathrm{L}} \pm \mathrm{S}_{\overline{\mathrm{L}}}\right)$ & $\left(\bar{W} \pm S_{\bar{W}}\right)$ \\
\hline 1 & 11 & 17,19 & $\begin{array}{c}13,32 \pm 0,25 \\
(12,00-14,50)\end{array}$ & $\begin{array}{c}27,40 \pm 1,74 \\
(19,45-38,14)\end{array}$ & - & - & - & - \\
\hline 2 & 17 & 26,56 & $\begin{array}{c}17,11 \pm 0,35 \\
(15,00-20,00)\end{array}$ & $\begin{array}{c}58,82 \pm 3,93 \\
(38,00-101,00)\end{array}$ & - & - & - & - \\
\hline 3 & 29 & 45,31 & $\begin{array}{c}20,17 \pm 0,18 \\
(18,50-22,50)\end{array}$ & $\begin{array}{c}104,14 \pm 3,85 \\
(75,00-152,00)\end{array}$ & 7 & 77,78 & $\begin{array}{c}30,98 \pm 0,80 \\
(28,00-34,50)\end{array}$ & $\begin{array}{c}374,07 \pm 31,33 \\
(283,49-546,68)\end{array}$ \\
\hline 4 & 6 & 9,38 & $\begin{array}{c}24,50 \pm 0,99 \\
(23,00-26,00)\end{array}$ & $\begin{array}{l}182,29 \pm 11,28 \\
(143,00-217,00)\end{array}$ & 2 & 22,22 & $\begin{array}{c}38,10 \pm 0,25 \\
(36,20-40,00)\end{array}$ & $\begin{array}{c}697,05 \pm 66,74 \\
(631,13-763,48)\end{array}$ \\
\hline 5 & 1 & 1,56 & 30,5 & 375 & - & - & - & - \\
\hline Toplam & 64 & 100,00 & & & 9 & 100,00 & & \\
\hline
\end{tabular}

Çizelge 2. Kadıncık Deresi'ndeki dağ alabalığı ve gökkuşağı alabalıklarının yaş, boy ve ağıılık kompozisyonu 
Çizelge 3. Kadıncık Deresi'ndeki balıkların yoğunluk $(\hat{\mathrm{N}})$ ve biyomas $(\hat{B})$ tahminleri

\begin{tabular}{|c|c|c|c|c|c|c|c|}
\hline İst. No & Akarsu G. & $\mathrm{Av}(\mathrm{C})$ & $B(g)$ & $\hat{\mathrm{N}}$ (adet) & $\hat{\mathrm{B}}(\mathrm{g})$ & $\hat{\mathrm{N}}$ (adet/ha) & $\hat{\mathrm{B}}(\mathrm{kg} / \mathrm{ha})$ \\
\hline \multicolumn{8}{|c|}{ Tabaka A (N=25, n=13)-Gökkuşağı alabalığı } \\
\hline 1 & 5,5 & 0 & 0 & 0 & 0 & 0 & 0 \\
\hline 2 & 6,0 & 0 & 0 & 0 & 0 & 0 & 0 \\
\hline 5 & 5,0 & 0 & 0 & 0 & 0 & 0 & 0 \\
\hline 6 & 6,0 & 2 & 663,5 & 3 & 1053,3 & 26 & 8,8 \\
\hline 8 & 4,5 & 0 & 0 & 0 & 0 & 0 & 0 \\
\hline 10 & 5,5 & 0 & 0 & 0 & 0 & 0 & 0 \\
\hline 12 & 4,0 & 0 & 0 & 0 & 0 & 0 & 0 \\
\hline 15 & 4,5 & 1 & 375,6 & 2 & 596,7 & 18 & 6,6 \\
\hline 16 & 4,0 & 0 & 0 & 0 & 0 & 0 & 0 \\
\hline 18 & 5,5 & 0 & 0 & 0 & 0 & 0 & 0 \\
\hline 20 & 5,0 & 3 & 1453,2 & 5 & 2360,2 & 48 & 23,1 \\
\hline 23 & 4,5 & 3 & 1520,8 & 5 & 2413,5 & 53 & 26,8 \\
\hline 25 & 5,0 & 0 & 0 & 0 & 0 & 0 & 0 \\
\hline Ortalama & $5,0 \pm 0,2$ & $0,7 \pm 0,3$ & $308,7 \pm 155,4$ & $1,1 \pm 0,5$ & $494,1 \pm 249,2$ & $11,1 \pm 5,4$ & $5,0 \pm 2,6$ \\
\hline Genel ort. & - & 0,22 & 96,49 & 0,34 & 154,41 & 3,47 & 1,56 \\
\hline \multicolumn{8}{|c|}{ Tabaka $B(N=1, n=1)$} \\
\hline 26 & 8 & 0 & 0 & 0 & 0 & 0 & 0 \\
\hline \multicolumn{8}{|c|}{ Tabaka C (N=14, n=5) } \\
\hline 29 & 6,0 & 0 & 0 & 0 & 0 & 0 & 0 \\
\hline 31 & 5,5 & 0 & 0 & 0 & 0 & 0 & 0 \\
\hline 33 & 4,5 & 0 & 0 & 0 & 0 & 0 & 0 \\
\hline 38 & 5,0 & 0 & 0 & 0 & 0 & 0 & 0 \\
\hline 40 & 5,5 & 0 & 0 & 0 & 0 & 0 & 0 \\
\hline Ortalama & $5,3 \pm 0,2$ & 0 & 0 & 0 & 0 & 0 & 0 \\
\hline \multicolumn{8}{|c|}{ Tabaka D (N=40, n=18)-Dağ alabalığı } \\
\hline 43 & 4,5 & 1 & 375 & 2 & 595,1 & 18 & 6,6 \\
\hline 44 & 5,0 & 2 & 111,6 & 3 & 177,1 & 32 & 1,8 \\
\hline 45 & 6,5 & 3 & 527,2 & 5 & 836,7 & 37 & 6,4 \\
\hline 48 & 6,0 & 4 & 411 & 6 & 652,3 & 53 & 5,4 \\
\hline 49 & 5,5 & 4 & 344 & 7 & 546,0 & 58 & 5,0 \\
\hline 50 & 4,0 & 2 & 106,9 & 3 & 169,87 & 40 & 2,1 \\
\hline 51 & 5,5 & 4 & 251 & 6 & 398,4 & 58 & 3,6 \\
\hline 52 & 5,5 & 4 & 216 & 6 & 342,8 & 58 & 3,1 \\
\hline 53 & 4,5 & 4 & 218 & 7 & 346,0 & 71 & 3,8 \\
\hline 54 & 5,0 & 5 & 491,5 & 8 & 780,1 & 79 & 7,8 \\
\hline 55 & 4,75 & 4 & 369 & 6 & 585,7 & 67 & 6,2 \\
\hline 57 & 5,5 & 4 & 263 & 6 & 417,4 & 58 & 3,8 \\
\hline 58 & 4,5 & 4 & 281 & 6 & 446,0 & 71 & 4,9 \\
\hline 60 & 4,0 & 4 & 475 & 6 & 753,9 & 79 & 9,4 \\
\hline 61 & 4,0 & 4 & 398,5 & 6 & 632,5 & 79 & 7,9 \\
\hline 62 & 6,0 & 4 & 445 & 7 & 706,3 & 53 & 5,9 \\
\hline 63 & 5,5 & 4 & 248,8 & 7 & 394,9 & 58 & 3,6 \\
\hline 65 & 5,0 & 3 & 339 & 5 & 538,0 & 48 & 5,4 \\
\hline Ortalama & $5,1 \pm 0,2$ & $3,6 \pm 0,2$ & $326,2 \pm 29,0$ & $5,7 \pm 0,4$ & $517,7 \pm 46,0$ & $56,5 \pm 4,0$ & $5,1 \pm 0,5$ \\
\hline Genel ort. & - & 1,80 & 163,10 & 2,90 & 258,85 & 28,25 & 2,55 \\
\hline Dere ort. & 5,00 & 2,0 & 259,6 & 3,20 & 177,68 & 31,7 & 4,1 \\
\hline
\end{tabular}

\section{Tartışma}

Dağ alabalığının yaş kompozisyonunda 3 yaşından büyük bireylerin oranının \% 10,94 olması, ergin balıklar üzerinde yoğun bir avlama baskısı olduğuna işaret etmektedir. Ancak, Kadıncık Deresi'nin Türkiye Cumhuriyeti Orman Bakanlığı tarafından Milli Park kapsamına alınarak er türlü balık avcılığının yasaklanması ve koruma altına alınması, ilerleyen yıllarda dağ alabalığı populasyonunun iyileşmesi için önemli bir adım olarak kabul edilebilir.

Gökkuşağı alabalığı, Kadıncık Deresi'nde korumanın başladığı noktadan 4,6 km mesafeye kadar dağılım göstermesi ve bu noktadan sonra kaynağa doğru akıntıya karşı yapılan örneklemelerde hiç gökkuşağı alabalığı avlanmamış olması, gökkuşağı alabalıklarının atık ve yem deşarjı nedeniyle alabalık çiftliğinden yaklaşık 5 km'den fazla uzaklaşmadığını göstermektedir.

Kadıncık Deresi'nde ilk dağ alabalığına akarsuyun 8,6. $\mathrm{km}$ 'sinde (43. istasyonda) rastlanmış ve buradan itibaren kaynağa doğru yoğunluğun arttığı gözlenmiştir. Bu durum, derenin muhtemelen insan etkilerinden uzaklaşmasından kaynaklanmış olabilir. Çünkü, Kadıncık Deresi bu noktadan itibaren dönüş yaparak habitat değiştirmiş, patika yol bitmiş ve dereye ulaşma olanağı çok zorlaşmıştır. Bundan sonraki araştırma istasyonlarına ulaşabilmek için dere bu noktada tahta bir kalas vasıtasıyla geçilebilmiş, avlama araç ve ekipmanları büyük güçlükllerle taşınabilmiştir. Kadıncık Deresi'nin 8,6. km'sinden itibaren ulaşımın sadece özel amaçlar için ve çok zor koşullarda yapılabilmesi, dağ alabalıklarının bu noktadan itibaren nispeten daha rahat bir yaşam alanı bulabilmelerini sağladığı söylenebilir. 
Kadıncık Deresi'ndeki dağ alabalığının ortalama yoğunluk ve biyomas değerleri (sırasıyla 28,25 adet/ha ve 2,55 kg/ha), Korkmaz ve ark. (1998) tarafından Hatila Deresi'nde saptanan yoğunluk ve biyomas değerleriyle (sırasıyla 19-612 adet/ha ve 0,52-56,23 kg/ha) karşılaştırıldığında, Kadıncık Deresi'ndeki değerlerin ne kadar düşük kaldığı görülür. Bu durum, Derenin koruma altındaki bölümünde, korumanın yeterli ölçüde yapılmamış olmasından kaynaklanmış olabilir. Nitekim, araştırma esnasında, yasa dışı olarak avladığı alabalıklarla birlikte yerel bir avcıya rastlanması bu görüşü doğrulamaktadır.

Kadıncık Deresi'nde saptanan toplam balık yoğunluğu ve biyoması (sırasıyla 32 adet/ha ve $4 \mathrm{~kg} / \mathrm{ha}$ ), Korkmaz ve ark. (1998) tarafından Hatila Deresi'nde saptanan değerlerle (sırasıyla 281-763 adet/ha ve 14,21-56,23 kg/ha) karşılaştırıldığında, oldukça düşük kalmaktadır.

Berrak ve çok temiz sular, doğal besin ve balık bakımından fakir olup, verimlilikleri düşüktür. Kadıncık Deresi'ndeki balık yoğunluğu ve biyomasının düşük olması, tür çeşitliliğinin dağ alabalığı ile dere kenarında kurulu bulunan alabalık üretim çiftliğinden kaçan gökkuşağı alabalıklarından oluşması ve aynı habitatı paylaşan başka balık türü olmamasının;

- Dağ alabalıklarının üreme döneminde yoğun ve sürekli yağışların derede oluşturduğu erozyon sonucunda, derenin uzun süre bulanık akmasından,

- Dere yatağının sık sık bozulması nedeniyle, üreme ve barınma ortamlarının azalmasından,

- Sellerle taşınan kayaç ve kayaların derenin yatağını sık sık değiştirmesinden,

- Üreme alanına karayolu ile ulaşımın imkânsız, yaya ulaşımının da çok zor olması nedeniyle, gerekli koruma yapılamadığından, ergin balıkların yerel avcılar tarafından yoğun şekilde avlanmasından,

- Dere akış hızının yüksek ve dere yatağının dik eğimli olmasından,

- Derenin besince çok fakir olması ve dağ alabalığının tüketebileceği yem balıkları olmamasından ve

- Bölgedeki orman yolunun kaynağına kadar ulaşmaması nedeniyle ergin balıkların koruma altına alınamamasından

\section{kaynaklandığı düşünülmektedir.}

$\mathrm{Bu}$ araştırma, su seviyesinin ve su akış hızının nispeten düşük olduğu mevsimde yürütüldüğünden, gökkuşağı ve dağ alabalıklarının mevsimsel dağılımını inceleme olanağı olmamıştır.

Dağ alabalığının (Salmo trutta macrostigma) Türkiye'de büyük bir popülariteye sahip olması, gökkuşağı alabalığından iki kat fazla fiyatla alıcı bulabilmesi, dinamit, el bombası, karpit, elektrik ve ışıkla avcılık gibi yasal olmayan avlama metotları kullanılması ve özellikle üreme döneminde ergin balıklar üzerinde yoğunlaşan aşırı avcılık sonucunda, populasyona yeni birey katılımı düşük olmakta ve populasyon küçülmektedir.

Dağ alabalığı benzer habitatta yeterli koruma altında üreme faaliyetini sürdürebildiğinden, ekolojik bakımdan alabalık için uygun olan su kaynaklarında yapılacak balıklandırmalarda mutlaka dağ alabalığı kullanıımalıdır. Biyolojik gen kaynaklarımızın korunması ve yerli türlerimizi kültürü yapılan daha güçlü balıkların (örneğin; gökkuşağı alabalığı) rekabetinden korumak için dağ alabalığı gibi endemik türlerimizin bulunduğu su kaynaklarına diğer alabalık türlerini stoklamamak gerekir.

Kadıncık Deresi'nin düzensiz ve hızı akışı, beslenme ve üreme alanlarının tahrip olması ve en önemlisi üreme alanına ulaşımın zorluğu nedeniyle, koruma dışında kaldığından, yeniden stoklama düşünülürse, bu faktörler dikkate alınmalıdır. Korumanın başladığı noktadan kaynağa doğru 8,6. km'den itibaren ulaşım engellendiğinden, kitlesel alabalık katliamı yapılmaktadır. Dağ alabalıklarının doğal üreme alanları koruma altına alınmadıkça, diğer öneriler anlamsız olacaktır.

\section{Sonuç}

Dağ alabalıkları Eylül ayından itibaren üreme göçüne başladıklarından, çalışmanın mevsimlere bağlı olarak tekrar edilmesi, balıkların yıllık dağılımlarının saptanması açısından yararlı olacaktır. Çünkü, yılda tek bir defa yapılan avlama operasyonuna dayalı olarak balık türlerinin yoğunluk ve biyomas gibi kantitatif özelliklerinin tespit edilmesi, çevresel koşullar ve balıkların göç etme veya yer değiştirme alışkanlıkları nedeniyle, balıkçılık yönetimi açısından alınacak tedbirlerde eksiklik yaratabilir. Balık populasyonları ile ilgili yoğunluk ve biyomas gibi kantitatif parametrelerin yılın mevsimlerine göre incelenmesi, balıkçılık yönetimi açısından daha etkili tedbirler alınmasını sağlayacaktır.

$\mathrm{Bu}$ araştırmadan çıkarılacak en önemli sonuç, mevcut koşullarda Kadıncık Deresi'ndeki dağ alabalıkları için korumanın, ulaşımının çok zor olduğu ve yolun bitittiği noktadan (yaklaşık 8. km'den) itibaren doğal üreme alanı olan kaynağa kadar olan bölümde yapılması gerektiğidir.

\section{Teşekkür}

Bu araştırma, ASAUM (Ankara üniversitesi Su Ürünleri Araştırma ve Uygulama Merkezi) tarafından Milli Parklar ve Av-Yaban Hayatı Genel Müdürlüğü teknik elemanlarına verilen teorik ve pratik eğitimin uygulaması olarak planlanmıştır. Saha çalışmasındaki yardımlarından dolayı Genel Müdürlük yetkililerine, Mersin Başmühendisliği yetkililerine ve kursiyer teknik personele teşekkür ederiz.

\section{Kaynaklar}

Bagenal, T. B., F. W. Tesch, 1978. Age and growth. In: Methods for assessment of fish production in freshwaters. (Ed. Bagenal, T. B.) $3^{\text {rd }}$ Ed. IBP Handbook, Blackwell, Oxford, pp.165-201.

Bohlin, T., S. Hamrin, T. G. Heggberget, G. Rasmussen and S. J. Saltveit, 1989. Electrofishing theory and practice with special emphasis on salmonids. Hydrobiologia, 173, 9-43. 
Coles, T. F., J. S. Wortley and P. Noble, 1985. Survey methodology for fish population assessment within anglian water. J. Fish. Biol., 27 (Supplement A): 175-186.

Gelwick, F. P. 1990. Longitudinal and temporal comparisons of Riffle and pool fish assemblages in a northeastern Oklahoma Ozark Stream. Copeia, 4: 1072-1082.

Gorman, O. T., J. R. Karr, 1978. Habitat structure and stream fish communities. Ecology, 59: 507-515.

Halyk, L. C., E. K. Balon, 1983. Structure and ecological production of the fish taxocene of a small floodplain system. Can. J. Zool., 61: 2446-2464.

Hankin, D. G. 1984. Multistage sampling designs in fisheries research: Applications in small streams. Can. J. Fish. Aquat. Sci., 41: 1575-1591.

Korkmaz, A. Ş. ve D. Atay, 1997. Şuğul Deresi'ndeki balık populasyonlarının dinamiğinin incelenmesi: Büyüklük, yoğunluk, biyomas ve üretim. IX. Su Ürünleri Semp. 17-19 Eylül 1997, Eğirdir/lsparta, Bildiriler Cilt I, s. 163-181.

Korkmaz, A. Ş., M. Ölmez and D. Atay, 1998. Observations on some quantitative parameters of fish populations of the Hatila Brook, the Çoruh River, Eastern Turkey. Fisheco'98 First Int. Symp. On Fisheries and Ecology, September 2-4 1998, Trabzon, Proceedings, p. 27-33.

Lagler, K. F. 1956. Freshwater fishery biology. WM. C. Brawn Company Publishers, Dubuque, lowa, $421 \mathrm{p}$.

Mahon, R. 1980. Accuracy of catch-effort methods for estimating fish density and biomass in stream. Env. Biol. Fish., 5: 343363.

Neves, R. J. and G. B. Pardue, 1983. Abundance and production of fishes in a small Appalachian Stream. Trans. Amer. Fish. Soc., 112: 21-26.
Ölmez, M. 1992. Yukarı Sakarya Havzası Sakaryabaşı Bölgesi balıklarının populasyon dinamiği üzerinde bir araştırma. Doktora Tezi, Ankara Üniv. Fen. Bil. Ens., 228 s. Ankara.

Penczak, T., M. Zalewski, E. Suszycka and M. Molinski, 1981. Estimation of the density, biomass and growth rate of fish populations in two small lowland rivers. Ekol. Pol., 29: 233-255.

Peterson, N. P. and C. J. Cederholm, 1984. A comparison of the removal and mark-recapture methods of population estimation of juvenile coho salmon in a small stream. N. Amer. J. Fish. Manage., 4: 99-102.

Saraçoğlu, H. 1990. Bitki örtüsü, akarsular ve göller. MEB Yayınları, Öğretmen Kitapları Dizisi: 177, Milli Eğitim Basımevi, 577 s. İstanbul.

Seber, G. A. F. 1973. The estimation of animal abundance and related parameters. Graffin London, 506 p.

Zalewski, M. 1985. The estimate of fish density and biomass in rivers on the basis of relationships between specimen size and efficiency of electrofishing. Fish. Res., 3: 147-155.

\section{İletişim adresi:}

Şeref KORKMAZ

Ankara Üniversitesi Ziraat Fakültesi

Su Ürünleri Bölümü-Ankara

Tel: $03123170550 / 1441$

Fax:0 3123185298

e-mail: korkmaz@agri.ankara.edu.tr 